\title{
Design Methods and Steps for Landscape Sculpture of Commercial Pedestrian Street
}

\author{
Shanshuang Li \\ School of Art and Design \\ Huanghe Science and Technology College \\ Zhengzhou, China \\ e-mail: 479774980@qq.com
}

\begin{abstract}
The "Design Methods for Landscape Sculpture of Commercial Pedestrian Street" mainly makes a systemic introduction for the design method and design process for landscape sculpture of commercial pedestrian street. Through the narration of survey stage, composition stage and final expression and production stage, the reader will have a general understanding of the design method and working process of sculpture. It is a process from theory to practice. Through illustration of this paper, we hope that each sculpture can be finally realized through the sequence of this paper.
\end{abstract}

Keywords-landscape sculpture of pedestrian street; design method; steps

\section{INTRODUCTION}

The social responsibility of sculptor is to establish public review system, reflect public will and obtain recognized and popular landscape sculpture of commercial pedestrian street. As a public art, the landscape sculpture of commercial pedestrian street is closely associated with people, and will inevitably and persistently act on the audience from morning to night. It can be said that it influences people's work and life comprehensively and in all-weather. People's hobbies are infinitely rich. The public art shall also be rich and colorful. Both the comprehensive landscape of main landscape sculpture of commercial pedestrian street and the ornamental sculpture combined with building can obtain their own position. Any art cannot leave artist's labor as well as personality and interest. Denying personality characteristics of artist is equal to denying the art. However, landscape sculpture of commercial pedestrian street is a public environment art serving the public. In creation, the artist shall firstly consider the public's participation and acceptance, know the public's concern, and give people the enjoyment of beauty and the enlightenment of wisdom through artful artistic conception. Therefore, the responsibility of public artists is higher than that of ordinary artists. They must be the enthusiastic participants of social civilization. China pays more and more attention to the opinion of citizens in urban planning design, construction and development. The public's participation in urban construction and management are protected politically and legally. "The city of people shall be built by the people" also reflects this principle. Attaching importance to human factor and encouraging public participation not only are the need of realizing the purpose of urban planning, but also an important aspect of China's socialist democracy, which shall be reached a consensus in administrative leadership, artist and public. Public participation shall be regarded as a necessary procedure in the construction process of urban public art. Its implementation shall be ensured with system or legislation. It will practically solve the will of the leader which is isolated from the people and the objectionable practices of individual performance. The sculpture accepted by the city, recognized by artist and liked by citizens is the efficient and humane landscape sculpture of commercial pedestrian street with sense of the times.

\section{SURVEY STAGE}

\section{A. Environmental Analysis}

As the central point of open space design, commercial pedestrian street is designed by human being. The people there mainly are visitors, diners and customers, etc. Therefore, people shall be the starting point. Landscape environment shall be designed with people's mentality. The designer shall experience and feel what the visitors most like to see in crowded, noisy and busy commercial pedestrian street. The designer shall call the best joint point of people and space, including vision, hearing and touch, etc., and mobilize all possible emotional factors. Meanwhile, commercial pedestrian street is also a space environment reflecting local cultural connotation, local customs and practices as well as local features. Therefore, we shall consider multiple factors in design and environmental analysis.

Commercial pedestrian street is a completely open space. The audience includes the young, the old, men, women, Chinese and foreigners, etc. Their aesthetic taste shall be considered in design. The layout shall also conform to the basic standard of people. Therefore, in the design for landscape sculpture of commercial pedestrian street, we shall also consider its richness and diversity in addition to locality and culture. 


\section{B. Functional Analysis}

As a public artwork, the landscape sculpture of commercial pedestrian street shall firstly have its unique ornamental value. When people feel tired in noisy and busy environment, they need an "oasis" to relax and relieve the psychology. Therefore, the ornamental value of landscape sculpture in commercial pedestrian street has irreplaceable status and value. Secondly, it is its cultural characteristics and local features. Since landscape sculpture of commercial pedestrian street is the visual center of commercial pedestrian street, it has the role of street mark to a certain degree. The landscape sculpture shall combine with local feature, historical background, local customs and practices in content and form, and only in this way, it has value. Next, landscape sculpture of commercial pedestrian street shall have commercial character which is its unique function. It is directly related to its environment position. The landscape sculpture of commercial pedestrian street shall guide and stimulate the consumer to consume and invest to some extent, playing the role of advertising and propagandizing. It also guides the consumers to consume while the consumers view and admire, entertain and relax. People more easily accept other commodities or suggestions only in relaxed and cheerful mood. Therefore, the unique commercial character of landscape sculpture in commercial pedestrian street is an important aspect that the designer shall not neglect.

\section{CONCEPTUAL STAGE}

\section{A. Determination of Content and Theme}

The content and theme of landscape sculpture in commercial pedestrian street cannot leave the whole city and the whole street. The landscape sculpture of commercial pedestrian street only plays a role of concentration. The commercial, cultural, historic, decorative and ornamental values, etc. are concentrated in sculpture. Therefore, its content and form shall have unique innovation. The theme and main idea shall be clear. Only in this way can we design a high standard landscape sculpture in commercial pedestrian street.

\section{B. Determination of Position and Orientation}

The position and orientation are crucial for whether the landscape sculpture of commercial pedestrian street can play its function to the highest degree. The position of landscape sculpture in commercial pedestrian street depends on the design and structure of commercial pedestrian street. Its role is to further beautify the street and make up for the deficiency in street construction, thereby coordinating the relation of street - building - sculpture - people.

The orientation of landscape sculpture in commercial pedestrian street decides the moving direction of stream of people and the sequence that people enter the commercial pedestrian street. In this way, landscape sculpture of commercial pedestrian street plays a role of space partition. The shops with the same orientation of landscape sculpture in commercial pedestrian street will be the objects people firstly view and choose as well as attach exceptional importance. Therefore, the orientation of landscape sculpture in commercial pedestrian street naturally prioritizes the shops in commercial pedestrian street. It is also a good means of business competition.

\section{Determination of Scale}

The scale of landscape sculpture in commercial pedestrian street is determined by the scale of street. Compact street can be decorated by relatively small landscape sculpture of commercial pedestrian street. Such a sculpture scale will make people feel amiable, be much closer to people's life, and directly enter people's range of activity. Such a scale not only shortens the spatial distance between people and sculpture, but also shortens the psychological gap between people and sculpture. It is also a humanized design. On the contrary, large scale landscape sculpture of commercial pedestrian street belongs to landmark and commemorative landscape sculpture. It bears rich historical events and contribution of great figures. It will give people a strong sense of shock and majesty, making people learn from great man all the time. Large scale landscape sculpture in commercial pedestrian street has less appetency but strong sense of shock. Upon selecting and determining, we shall select based on local cultural characteristics and historical background.

\section{Determination of Material and Color}

The material, color, texture and expression of landscape sculpture in commercial pedestrian street shall be determined from the background of environment. On the basis of maintaining the coordination of sculpture theme, style and environment, to make the image of landscape sculpture in commercial pedestrian street be striking and distinctive. The background and sculpture shall have a certain contrast. Flexible material and rich color is the key of design at present.

\section{E. Determination of Technique of Expression}

The technique of expression shall be determined from the style of street and building. The technique of expression of landscape sculpture in commercial pedestrian street shall be consistent with architectural style and street layout. They shall supplement each other. In the West, traditional architecture is closely related to sculpture. We can place a stylish landscape sculpture works of commercial pedestrian street in a traditional culture context, and can also place a traditional sculpture in a modern style environment. But we shall be double-cautious, otherwise, we may make a stupid mistake and create a foolish design.

\section{EXPRESSION STAGE OF DESIGN Plan}

The design and production process of landscape sculpture in commercial pedestrian street not only is a self-creation process of sculptor, but also a coordination and cooperation process of many aspects such as planner, architect and landscape designer. We shall coordinate many factors to a large extent. Therefore, how the sculptor presents his/her own ideas to relevant people including building and street planner is a very important process. It is also a key for whether the landscape sculpture of commercial pedestrian 
street can be finally realized. As the carriers of creator's concept and idea, the presentation drawing of landscape sculpture in commercial pedestrian street, sculpture model and street building sand table can vividly and truly show the relation between commercial pedestrian street and sculpture, scale and perspective. They are effective means of communication. From conceptual design to concrete expression and to each process of plan implementation, effect picture, sculpture model and sand table play an important role.

\section{A. Conceptual Sketch}

Conceptual sketch is the quick expression of sculptor's idea in early stage of sculpture design. The process of thinking is rapidly expressed and illustrated through recapitulative sketch, brief and to the point written narrative.

\section{B. Draft of Sculpture Presentation Drawing}

\section{1) Hand-drawing effect picture}

Hand-drawing effect picture is drawn through fine point, mark pen, postercolor and watercolor. The characteristic is strong artistic atmosphere. The picture is free, lively and appealing. The defects are that its intuition is less strong than that of computer effect picture; the audience shall have a certain artistic accomplishment. Different angles shall be re-drawn

\section{2) Computer effect picture}

The computer production software, such as 3DMAX, MEYA and AutoCAD, shall be used to make 3D sculpture model in computer, synthesize real photo, render and create vivid virtual scene, making people have a feeling of being personally on the scene.

The advantages are that it has strong intuition, and that the difference between the effect picture and the scenery after the completion of sculpture is relatively small. It can be drawn and printed from multi-angles and multi-views.

The defect is that it's hard to use it for complex form and structure due to the limitation of software modeling. It is less free and vivid than hand-drawing in artistic expression.

\section{Production of Sculpture Model and Environment Sand Table}

Sculpture model meticulously and completely expresses the scene after the completion of sculpture in modeling, material and color. It facilitates the inspection on the effect after sculpture molding from many aspects, and also prepares for subsequent enlarge work. The sand table production shall be zoomed as per proportion, and try to represent the sculpture's position, scale and relation with surrounding building, street and landscape.

\section{ENLARGEMENT PRODUCTION AND INSTALLATION}

After the sculptor and Party A jointly approved and confirmed the plan of sculpture, it comes the actual processing and production stage. The enlargement stage is mainly to solve the problem of engineering technology. The larger the sculpture scale is, and the newer the adopted sculpture material is, the more prominent the engineering problem will be. And these often exceed the knowledge of sculptor and exceed the ability of sculptor. The sculptor shall widely and closely cooperate with related personnel such as structural engineer and technician, to solve the problems of sculpture due to the restriction of technical conditions such as structure, material and processing. The whole enlargement production stage shall be very cautious. It may violate the sculptor's will due to any carelessness, lead to error of sculpture production and affect the quality of sculpture.

For some aesthetic deviations appeared in China's existing landscape sculpture of commercial pedestrian street, many scholars have made some discussion and reflection for how to form correct aesthetic value orientation. In fact, many designers and sculptors still hope to solve these problems through the modeling of landscape sculpture in commercial pedestrian street. However, we cannot find the answer only from modeling, but shall return to the understanding and respect for time and reality. The design of landscape sculpture in commercial pedestrian street shall pay more attention to the coordination of integrated environment, aesthetic taste of audience and how to create a better commercial character, etc. A successful commercial pedestrian street can be constructed through creating a harmonious and integrated space environment between people and street, people and people, people and society through landscape sculpture of commercial pedestrian street.

As a carrier of landscape sculpture, in addition to having beautiful appearance, commercial pedestrian street shall also have gorgeous color and solid material. Only in this way can it permanently satisfy people's needs for leisure, entertainment, work and consumption, etc. Landscape sculpture of commercial pedestrian street shall respect human's life and consumption behavior. Therefore, its basic objectives shall be to create a pedestrian street environment having harmonious, casual and pleasant shopping environment. Whether its expression accords with the public's aesthetic taste, and whether the starting point is people become the key of landscape sculpture design in commercial pedestrian street.

Nowadays, in addition to exerting inherent material property, landscape sculpture in commercial pedestrian street shall have continuity of history, continuity of spirit, and diversity of forms. Only in this way can it truly meet the demand of current social development, the demand of human's spiritual civilization and the demand of facilitating the development of harmonious society. We believe that landscape sculpture of commercial pedestrian street is not a product of consciousness due to seeking for fashion, vogue, luxury and extravagant. Only simple and harmonious commercial pedestrian street construction guided by healthy aesthetic value orientation can withstand the test of history.

\section{REFERENCES}

[1] E•Bacon. Translated and edited by Huang Fuxiang, Zhu Qi. Urban Design [M]. China Building Industry Press, 1989 
[2] $\mathrm{Yu}$ Meicheng, et al. Urban Sculpture and Architectural Mural in Contemporary China[M]. Shanghai Bookstore Publishing House, 2005

[3] Liu Yongde. Form, Structure, Implication and Combination of Architectural Space[M]. Tianjin Science and Technology Press, 1998

[4] Ying Liguo. Urban Sculpture (I)[M]. China Building Industry Press, 2002

[5] The National Guiding Committee for Public Sculpture. Urban Sculpture in China, 50 Years (De luxe edition)[M]. Shaanxi People's Fine Arts Publishing House, 1999

[6] Written by Li Tongtong. Photographed by Xu Bin. American City Sculpture[M]. Liaoning Science and Technology Press, 2006

[7] Zhu Jieming. Corporation of Local Development--The background and effects of the gradually land use system reform in China

[8] Gan Mengyu. Study on Guangzhou Commercial Pedestrian Street Design[J]. National core trade and economic journal, 2006

[9] Zhao Hongmei. Study on "Humanized" Commercial Pedestrian Street Design[J]. National core trade and economic journal, 2006

[10] Liu Mingguo. Brief Exploration on Modern City Commercial Pedestrian Street Planning [J]. Shanxi Architecture, 2006

[11] Li Juan. Evolution and Development of Commercial Pedestrian Street Construction [J]. Shanxi Architecture, 2005

[12] Gong Jing. Spatial Form of Wuhan Commercial Pedestrian Street[J]. Shanxi Architecture, 2006

[13] Huang Peisen. Discussion on Landscape Design of Commercial Pedestrian Street in Downtown[J]. Journal of Anhui Agri. Sci. 2007

[14] Peng Chun. Brief Discussion on Planning and Design of Pedestrian Street (District)[J]. Chongqing Architecture, 2006

[15] Ding Shaolian. The Development and Transition of Downtown Pedestrian Mall in Europe and America [J]. Urban Problems, 2007

[16] Zeng Jun. Urbanity of Cultural Study. Journal of Northwest Normal University, 2006. 